fines, bet that two gring of optum should bo saministered ivery thres hours; and she was directed to take nothing into her mouth, but occasionally a small portion of ice or of icod water.

May 16th. We met again. The vomiting had entirely ceased; there had been no evacuation from the bowels; the abdomen was much enlarged, but not tender on pressure. She had slept a considerable time. Attempts were again made to pass a tube higher up; and Mr. Flower, who thought he had before passed a tube into an open space in the bowel, succeeded in passing a gum elastic catheter into an aperture high up, where it was held tight, like a bougie in a stricture of the urethrs. A quantity of warm water was injected through the catheter, and retained for some time; it then run out through the catheter colourless. This was repeated with the same result. The opium was ordered to be continued, and the ice and a few spoonfuls of arrowroot to be given. An eraporating lotion was applied to the abdomen.

May 21st. I agnin saw this lady. No alteration had taken place; the opium had been continued; there had been no vomiting. Arrow-root and small quantities of beef-ter had been taken; injections had been used three or four times a day without any effect. The abdomen was much the same in size, and not very tender on pressure. The pulse was firm, and the countenance good. It was decided that she should go on with the opium only, and take small quantities of nourishment.

Three or four days afterwards, it was suggested that it was possible that the enlarged uterus might compress the rectum in the pelvis; a sponge was therefore introduced into the vagina, and firm pressure was made, assisted by pressure on the fundus uteri through the rectum. The uterus appeared to be raised up by this; but nothing passed afterwards, excepting one day a pasty substance, of the size of a hazel nut, having a slight frecal smell, but this was somewhat doubtful.

June 19. I saw this lady again with Mr. Walker and Dr. Davies. She had now been twenty-eight days without any evacuation from the bowels; she had taken some nourishment without any romiting until two days before, when it returned; and since then she had thrown up some but not all the nourishment she had taken. Her pulse, though very quick, was still firm; and her countenance was tolerably good, and there was less emaciation than might have been expected. The abdomen was very large and tense, uniform, and everywhere resonant.

It had before been intimated to her friends that when all hope of the bowels being relieved had passed away, it would be justifiable to make an opening into the colon sbove the supposed obstruction, to evacuate the contents of the bowels; and they were informed that, if the natural passage should afterwards be restored, this opening would in all probability close up; but that if the passage should remain impervious, it would become an artificial anus. They were now informed that the time was arrived when it would be proper to resort to this operation, as it was evident that the great degree of distension of the abdomen must shortly produce fatal peritonitis. On the friends agreeing to this, the proposal was made to her, and she assented.

She was put under the influence of chloroform, and an incision of three inches in extent was made of a semilunar form in the left iliac region, commencing below the spine of the ilium, extending downwards towards Poupart's ligament, and terminating at the outer side of the usual position of the epigastric artery. The integuments and muscles having been divided, the peritoneum was opened, and a large convolution of the small intestine immediately protruded. It was greatly distended with air, and minutely injected with blood; but there was no lymph on the peritoneal surface. This portion was with some difficulty beld aside; but the descending colon could not be felt, nor any trace of it discovered. The fingers, passed as far down into the pelvis as I could reach, felt only a mass of firnz adhecions without any perceptible distinction of parts. The protruding small intestine was with considerable difficulty ntureed into the avity, and rotained there witi the divided integuments were brought aceurately together by satures. The pationt recovered from the effects of the chloroform, but continued in an hysterical state for an hour with small rapid pulse. She afterwards reevered; her pulse became stronger; and she took some arrow-root, bat continued to be very reak through the night, had but little pain, and she died at nine the next morning.

A past mortem examination was made by Mr. Walker, who has favoured me with the following account of the appearances on dissection.

On opening the abdomen in the lines alba, the first and most prominent viscus was the colon, running down perpendicularly from the ensiform cartilage to the pubis, its inferior portion being confined by adhesions in the right iliac region. Adhesions had formed in every direction, and each bowel was bound down to the peritoneal covering, excepting the portion of the small intestine which protruded at the time of operation. By tearing away the adhesions the parts within the pelvis were brought into view; the uterus occupied but a small space below the brim of the pelvis. The bladder was nearly empty. The rectum was cut across about half a finger's length from the anus; the gut was slit further up for rather more than two inches; and about midway there was found a strictured portion bound down by a tight cord of peritoneum, which was attached to the right side of the pelvis close to part of the broed ligament of the uterus near to its insertion. The strictured portion of the gut was of a chocolate colour on its outer side. The lining membrane of the intestine at the strictured part was abraded or worn away by the pressure of the constriction, or by the tube introduced to effect an opening. About nine inches above this strictured portion of the gut was a second stricture, formed by a similar band of adhesion, closely constricting the rectum at its upper part, which band adhered to the right side of the pelvis, and confined the upper part of the rectum to that side. The portion of the bowel between the two strictures was dilated to a large size and quite empty. Immediately above the second stricture was a quantity of gelatinous fluid, of considerable consistence, but not fæculent. In the colon were several lumps of fæces of the size of walnuts, but the bowels were not much loaded, and the small intestines contained little more than air. The body and fundus of the uterus were enlarged; in the latter were two rounded projections, which on dividing the peritoneal covering shelled out, and were fibrous tumours not embedded in the walls of the uterus. The os uteri was red and slightly ulcerated.

Bath, September 1854.

\section{CASE OF DIFFICULT LABOUR FROM HYDROCEPHALUS.}

By J. G. SWAYNE, M.D., Physician Accoucheur to the Bristol General Hospital; Lecturer on Midwifery in the Bristol Medical School.

[Read at the Quarterly Meeting of the Bath and Bristol Branch, September $28 \mathrm{th}, 1854$.

THE following case of difficult labuur from hydrocephalus has appeared to me worthy of notice, both on account of the rarity of the complication and the occasional obscurity of its diagnosis.

CAss. Emma B., aged 20, living in Bryant Street, Redcliffe Square, a primipara, had always had delicate health from a child, having been subject to chorea until about six months since. Labour came on first at 11 P.M. March 27th, 1854. The pains were very slight until the afternoon of the next day, when she sent for Mr. Homfray, one of my pupils who was engaged to atteud her. He saw her first at $4 \frac{1}{2}$ P.m., March 28th. The pains were then tolerably frequent. The os uteri was slightly dilated. At about $T$ P.M. the os uteri dilated to the size of a crown, and the head could be felt indistinctly. The labour then progressed very slowly until about 5 A.M., March 29th, when her pulso became more rapid, her face flushed, and her manner rest- 
lew and excited. Mr. Homfras then sent to request me to wer. I visited her about 11 A.x., and found, on examination, that the membranes were ruptured, and that the heed was pressing down 80 low as to touch the 08 externum. The presenting part was soft and tumid; the pulso was not much accelerated; nor were any very urgent oymptoms present. I therefore advised delay, and left her for a time. I returned about 2 P.M. on the same day, and made a careful examination of the head, when I came to the conclusion that it was hydrocephalic. The sagittal outure was at least an inch wide, so that I could easily pass the tip of my forefingers beneath the parietal bones. The head felt very large, loose, and baggy, and presented an obscure fluctuation. The presenting part was very codematous; and the whole head so firmly fixed in the pelvis, that it could not be pushed back between the pains. As the symptoms were becoming urgent, I determined to wait no longer, and applied the rectis first over the back, and then over the front of the head, but without success. The short forceps could not be well applied, on account of the shape and size of the head, and the impossibility of reaching the ear. I was still loth to perform craniotomy, because I could yet detect the pulsations of the fotal heart by the stethoscope. About 4 P.M., however, the woman's state became more critical; her pulse was much quicker and feebler, her manner more restless and excited; so that it was impossible to restrain her in one position. I therefore made a small opening with Smellie's scissors in the sagittal suture, taking care not to injure the brain. At least a pint of fluid gushed forth; the skull collapsed; and, notwithstanding all precautions, a considerable quantity of semifluid brain came through the opening. I then inserted my forefinger into the opening, and after some little time, by drawing down the head, in concert with the pains, effected delivery. The child was a full-sized female infant. The occiput was towards the right acetabulum. The pressure against the pelris had caused considerable ecchymosis around the left eye and ear, and also a fracture of the right parietal bone. Some hæmorrhage accompanied the expulsion of the placenta, but was easily controlled by pressure. After delivery, the patient appeared very much exhausted, and her pulse had risen to 142, and was very weak. We gave her brandy, with twenty-five minims of tincture of opium. On the following day, she was much better, and ultimately recovered well, with the exception of a slight attack of phlegmasia dolens.

The child's skull, on measurement, was found to be sixteen and three-quarter inches in circumference, seven and a quarter inches in the occipito-mental diameter, six and a quarter in the antero-posterior, and four and a half in the transverse.

REMcarks. The rarity of hydrocephalus as a complication of labour, is shewn by the statistics of Mme. Lachapelle and M. Dugès, who only net with fifteen cases in 43,555 labours. The symptoms produced by the greatly increased size of the head, are much the same as those which arise in tedious labour from diminished capacity of the pelvis; with this exception, that they are generally more urgent in hydrocephalus, because the head, from its compressibility, fills the cavity of the pelvis very completely, so as to make most injurious pressure upon all the contents of that cavity. As Dr. F. Ramsbotham truly remarks, "Most of the cases of this description which I have seen have been attended with great agony, especially in the pubic region, from the time the liquor amnii has evacuated till delivery, and some of them even before the membranes broke; and the patient, as in Mr. Robertson's case, has been exceedingly irritable and restless, rolling about in every direction, and with difficulty preserved in one position a sufficient time to make the necesary vaginal examination. This aggravation of suffering arises from the pressure of the distended cranium on the bladder and other tender structures at the pelvic brim, which, in cases of lingering labour from a mere ordinary cause, are not subjected to the same amount of distress." The case I have related fully bears out Dr. Ramsbotham's obserra- tions; the pationt was throughout ren reatlew and dif cult to control, and the pressure of the head upon the promontory of the sacrum and the pubes must have been very severe, if we may judge from the fracture of the parietal bone on one side, and the very great ecchymosis around the eye and ear on the other side of the head.

The diagnosis of hydrocephalus is occasionally somewhat obscure; and, in order to arrive at a correct opinion, should be deduced not from one sign only, but from : combination of several. In most works on midwifery, hydrocephalus is stated to be distinguished by the following circumstances. The head forms a large tumour, filling the brim of the pelvis, and not descending into the cavity, although the pains may be very strong. This tumour, during the intervals of the pains, is soft and fluctuating, particularly at the points corresponding with the sutures and fontanelles, which are very open; the bones themselves are likewise in a greater or less degree separated. Finally, in cases of very marked hydrocephalus, the bones float, as it were, in the midst of the soft parts. With respect to the non-descent of the head into the pelvis, my own experience has led me to conclude that this statement is generally incorrect: the head is not sufficiently ossified, and therefore not sufficiently firm and resisting, to remain above the brim; on the contrary, it generally becomes fully engaged in, and completely fills up the cavity of, the pelvis, as far as the os externum, as in the case above related. The great width of the sagittal suture, and the sense of fluctuation, were very distinct in that case; but these signs alone are not sufficient to rely on in the diagnosis of hydrocephalus; for the bones may be very far apart, and fluctuation may appear tolerably distinct, without the presenco of any disease within the cranial cavity. The following case will show this.

On examining a patient whom I was attending in July 1851 , I found the os dilated to the size of a crown, and the head apparently presenting through the tense bag of the membranes. On again examining, when the os was more fully dilated, I found that the membranes were ruptured, for I could feel the hairy scalp. I could, however, feel no bone, but a soft round elastic tumour, so that at one time I had misgivings as to its being the head; but, on passing my finger higher up, I felt distinctly the cranial bones. Presently the child was expelled, with the occiput towards the right groin. It was a fine, healthy, male infant, but. there was an extraordinary deficiency of bone at the vertex; and this circumstance had caused the presentation to be so. puzzling. The whole of the posterior and upper part of the left parietal bone above the protuberance was wanting, and also a considerable portion of the right parietal bone close: to the posterior fontanelle. This child's head was completely ossified at the age of twelve months. He is now living and healthy.

Had this child's head been punctured, upon the supposition of hydrocephalus, the mistake would have been very disastrous; we should therefore, I think, draw our conclusions from other signs, besides that just mentioned. Ono: of the best of these is the very great volume of the head, evinced by its great depth from above downwards; although the head may be so low as to press on the perineum (as in the case related), it is quite impossible to touch the ear, because this part is above the pelvic brim, and out of reach. Still, in many instances the diagnosis is not sufficiently clear to warrant us in resorting to craniotomy much earlier than we should in an ordinary case of obstructed labour; on the contrary, it is much better, as a general rule, to leave the case as long as possible to nature, in the hope that the head may be expelled, and not to open the cranium until there are some warnings of danger to the mother. In consequence of the yielding nature of the head, it may, although of large size, be sometimes expelled without injury either to mother or child. This happened in another case, attended by one of my pupils, in which a head nearly as large as that exhibited was expelled by the pains. The mother did well; but the child, although living at birth, did not survive many days. 
It if nonally recommonded, that, in pencturing the head, should make small opening, so as just to drain off the finid without injuring the brain, and thus are, if possible, the life of the child. This preceution, hovever, seldom succeeds; as, in the instance related, the bones collapse, and the cranium is so much squeezed together during its passage through the pelvis, that the soft and pulpy brain, nor deprived of the support of the fluid, soon becomes mashed up and destroyed, and flows away with the fluid contained in the cranium. But this is the less matter for regret, because the chance of life, and especially of ultimate health, after such an operation, however successful at the time, must be extremely slender.

Clifon, Bristol, September 1854.

\section{ARTIFICIAL TEETH SWALLOWED, AND EJECTED BY THE BOWELS. \\ BY RICHARD THURSFIELD, Esq.}

CAsE. I was hastily summoned, on Saturday morning last (Bept. 30), at six o'clock, to a gentleman who was reported to have swallowed his artificial teeth. I learnt from him that he awoke suddenly with a sensation of choking, and at once found he was in the act of swallowing four enamel teeth fixed in a gold plate, covered on one side with gutta percha. He still felt a disagreeable sensation, as if something was in the esophagus; but it was only a feeling, for he could 8 wallow readily either fluids or solids. I ordered him to keep quiet in bed, to lie on his right side, and to live on gruel; and, in the course of an hour or two, to take a dose of castor oil. On Sunday, I found him entirely free from pain; and he continued living on gruel, but got up and walked about the house. On Monday (Oct. 2), he was still as comfortable, and repeated the dose of oil; and about two o'clock, without the slightest difficulty or pain, the teeth passed. I send an exact representation of them.

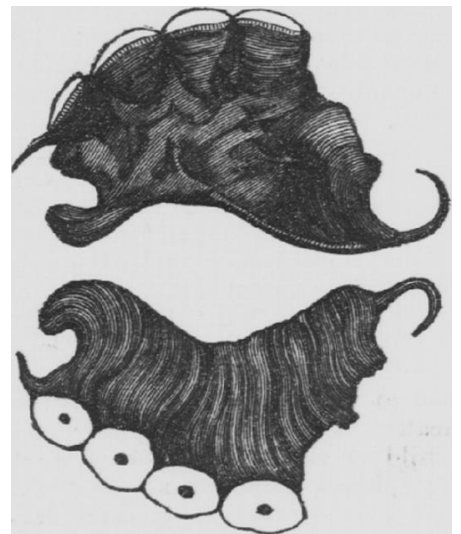

The termination of the case in so favourable a manner was hardly to be expected, from the shape and insolubility of the substance swallowed.

Broseley, Shropshire, October 6th, 1854.

\section{CASE OF STRANGULATED HERNIA MASKED BY AN ENLARGED GLAND.}

\section{By J. D. BROWN, Esq.}

Having read a case in the Association Journal for May 26th, 1854 , p. 467 , mentioned by Dr. R. H. Semple, of crangulated hernia masked by an enlarged gland, which ended fatally, I consider it may be useful to detail the particulars of a similar case, which had a favourable termination under different treatment.

Capr. I woman, aged 54 years, delicate, had long suffered from a glandular tumour in the groin. Onder the egg, and remained $s 0$ up to her attack of hernia.

In March last, after breakfast, and immediately subsequent to the bowels having acted, she was seized with severe pain in the abdomen, attended with romiting, and the usual symptoms of enteritis. My assistant saw her in my absence, and treated her accordingly; having failed to detect hernia, as she had no enlargement in the femoral region, nor yet pain the tumour, which was of the same size as usual. She was bled, had leeches applied, was salivated, and blistered, but not a single symptom gare way. The pain was severe, the abdomen tense, and very tender. Every possible means were resorted to, to remore the obstruction, without avail. At the end of three dajs (when I first had an opportunity of seeing her), I directed a tobacco injection to be administered, under the influence of which a little fæcal matter passed. I then commenced giving her large doses of opium, which effectually relieved the pain. She suffered none after the first dose of two grains. This was persevered in for twenty-four hours at long intervals. She slept a good deal, but still would.keep nothing on her stomach. The vomited matters were now nothing on her stomach. The vomited matters we breath smelt so offensively strong of fæcal matter, that only a sense of duty enabled one to endure it.

On the fifth day, I called Mr. Rowe (of this town) into consultation, and again every region of the abdomen was carefully inspected. Nothing but the tumour presented itself, painless and apparently harmless.

We now determined on making an exploring incision, with faint hopes of discovering something; but still resolved on waiting till the evening, hoping some better change would take place. By this time the pulse was scarcely perceptible.

We agreed to operate by removing the tumour and dissecting our way down to the ring. We cut through carefully, fearing some intestine might have got behind it, and which proved to be the case, for there lay a small knuckle of it, quite black. It was liberated; the symptoms gave way; the bowels acted before the morning. Sloughing of the wound supervened; but in spite of all she recovered.

I have published this case in full, as I can perceive no difference between it and Dr. Semple's. Both are instructive, showing the danger of trusting to any but ocular testimony in doubtful cases. I would never hesitate to explore in any similar ones that may occur: by hesitating, Dr. Semple lost his patient, and I nearly lost mine.

Haverfordwest, October 1854.

\section{PFRISCOPIC REVIGW.}

\section{OPHTHALMOLOGT.}

OPHTHALMOLOGICAL GLEANINGS.

CONGENITAL ABSENCE OF THE IRIS.

Professor W. BoEck, of Christiania, publishes in Hebra's Zeitschrift an account of a fanily, tuur members of which laboured under this defect.

In the father, aged 52, there was no iris in either eye; the right lens was cataractous, the left cornea opaque.

In the aunt, aged 62 , the right cornea was partly opaque, and there was incipient cataract; the left cornea was clear, but the lens of that eye was partially opaque and somewhat dislocated.

In the son, aged 17, both cornem and lenses were healthy, and a reddish reflection was visible from the bottom of the eye. The patient was myopic, but his sight good in other respects; and he suffered no inconvenience from light. Both eyeballs were in constant oscillation.

The uiece, aged 37, had the same deficiency of the iris; but her cornea were nebulous and vascular. She could of course hee but indistinctly, bnt had not lost the power of adapting the eye to different distances. This faculty, as our readers will 